\title{
The Effect Of Dexamethasone And Pethidine In Lowering The Incidence Of Shivering In Caesarean Section Patients Under Spinal Anaesthesia
}

\author{
Abduh Halim Perdana A*, Muhammad Ihsan**, Yutu Solihat** \\ *Resident of Anaesthesiology and Intensive Therapy, Faculty of Medicine, Universitas Sumatera Utara, Medan, Indonesia \\ ** Departement of Anaesthesiology and Intensive Therapy, Faculty of Medicine, Universitas Sumatera Utara, Medan, Indonesia \\ DOI: 10.29322/IJSRP.11.11.2021.p11947 \\ http://dx.doi.org/10.29322/IJSRP.11.11.2021.p11947
}

\begin{abstract}
BACKGROUND: Shivering is an increased muscular activity that can caused by spinal anaesthesia. Dexamethasone is a steroid drug that can lower the incidence of post anaesthetic shivering by decreasing the dermal temperature and core temperature gradient. This study aimed to compare the effect of dexamethasone and pethidine in lowering the incidence of shivering in caesarean section patients under spinal anaesthesia.

METHOD: This was a post-test control group clinical trial study conducted in Central Surgical Unit at RSUP H Adam Malik Medan and University of North Sumatera Hospital for 3 months. A total of 81 samples were divided into 3 groups (pethidine; dexamethasone; normal saline, NS). Randomized triple blind method was used. The variables were tested using chi square $(\mathrm{p}<0,05)$.

RESULT: Shivering was found in all study groups (pethidine 25,9\%; dexamethasone 37\%; NS 59,3\%). The percentages of grade 0 shivering were $74,1 \%, 63 \%$, and $40,7 \%$ in pethidine, dexamethasone, and NS group respectively ( $\mathrm{p}$ value 0,011 ). There was no incidence of grade 4 shivering in pethidine group.

CONCLUSION: The effects of pethidine, dexamethasone, and NS in lowering the incidence of post anaesthesia shivering in caesarean section patients under spinal anaesthesia were statistically significant ( $p$ value 0,04 ). There was a significant difference in shivering incidence based on shivering assessment scale among all study groups ( $\mathrm{p}$ value 0,011 ).
\end{abstract}

Index Terms- shivering, dexamethasone, pethidine, caesarean section, spinal anaesthesia

\section{INTRODUCTION}

$\mathrm{P}$ ost anaesthetic shivering is an uncomfortable condition that increases oxygen consumption. Although some studies proposed some theories, the exact mechanism of shivering is still unknown. Several drugs, such as clonidine, ketamine, doxapram, tramadol, pethidine, and other opioids, have been studied for shivering management. Pethidine is believed to be effective as shivering management and prevention. It is implied that pethidine can affect thermoregulation centre directly or opioid receptormediated.
Post anaesthetic shivering (PAS) was reported 33-65\% after general anaesthesia and 33-56,7\% after spinal anaesthesia. Study by Bhattacharay et al showed shivering occurred $40 \%$ in patient post general anaesthesia, $50 \%$ in patient with core temperature $35,5^{\circ} \mathrm{C}$, and $90 \%$ in patient with $34,5^{\circ} \mathrm{C}$. The incidence of post spinal anaesthesia shivering is vary; Kelsaka et al reported 36\%, Roy et al reported 56,7\%, and Sagir et al reported $60 \%$.

Dexamethasone is one of steroid drugs that has antiinflammatory and immunosuppressant effect. It has greater glucocorticoid effect than cortisol, but has weaker mineralocorticoids effect. Dexamethasone can lower the incidence of PAS by decreasing dermal temperature and core temperature gradient.

In 2013, Masood Entezariasl conducted a double-blind study in 120 surgical patients under general anaesthesia. They were given dexamethasone, pethidine, and placebo as shivering prophylaxis. It showed that there is no significant difference in patients' characteristics (sex, age, duration of procedure, extubation time, recovery time, and other clinical characteristics). Shivering occurred $47,5 \%$ in control group, $10 \%$ in dexamethasone group, and $37,5 \%$ in pethidine group. There were significant differences in shivering incidence among all study groups ( $\mathrm{p}$ value 0,001 ).

\section{METHODS}

This was a post-test control group clinical trial to compare the effect of dexamethasone, pethidine, and normal saline (NS) in preventing post anaesthetic shivering in caesarean section patients under spinal anaesthesia. The samples were caesarean section patients under spinal anaesthesia and consecutive sampling was used. This study was conducted in Central Surgical Unit at RSUP H Adam Malik Medan and University of North Sumatera Hospital for 3 months (August-November 2020). Samples were divided into 3 groups using randomized triple blind method; group A received pethidine $0,5 \mathrm{mg} / \mathrm{kg}$, group B received dexamethasone $0,1 \mathrm{mg} / \mathrm{kg}$, and control group received normal saline $0,9 \%$. All drugs were administered intravenously. The variables were tested using chi square ( $\mathrm{p}$ value $<0,05$ ). 


\section{RESULTS AND DISCUSSION}

There were 81 samples retrieved using inclusion and exclusion criteria. The samples were divided evenly into 3 groups; each group consisted of 27 samples.

Table 1 Distribution of Samples' Characteristics

\begin{tabular}{cllll}
\hline Characteristics & Pethidine & Dexamethasone & NaCl 0,9\% & p-value \\
\hline $\begin{array}{c}\text { Age, mean } \pm \text { SD } \\
\text { Ethnicity, n (\%) }\end{array}$ & $29,37 \pm 5,39$ & $28,11 \pm 4,65$ & $28,37 \pm 3,31$ & $0,562^{\mathrm{a}}$ \\
Batak & $11(40,7)$ & $10(37,0)$ & $9(33,3)$ & \\
Jawa & $5(18,5)$ & $4(14,8)$ & $6(22,2)$ & $0,981^{\mathrm{b}}$ \\
Minang & $4(14,8)$ & $4(14,8)$ & $3(11,1)$ & \\
Melayu & $7(25,9)$ & $9(33,3)$ & $9(33,3)$ & \\
Religion, n (\%) & & & & \\
Moslems & $14(51,9)$ & $18(66,7)$ & $17(63,0)$ & \\
Christians & $11(40,7)$ & $8(29,6)$ & $7(25,9)$ & $0,639^{\mathrm{b}}$ \\
Catholics & $2(7,4)$ & $1(3,7)$ & $3(11,1)$ & \\
Education, n (\%) & & & & \\
Bachelor & $9(33,3)$ & $11(40,7)$ & $12(44,4)$ & \\
High School & $17(63,0)$ & $15(55,6)$ & $13(48,1)$ & $0,832^{\mathrm{b}}$ \\
Junior High & $1(3,7)$ & $1(3,7)$ & $2(7,4)$ & \\
BMI, mean \pm SD & $24,30 \pm 3,42$ & $24,33 \pm 2,34$ & $24,55 \pm 3,21$ & $0,855^{\mathrm{c}}$ \\
\hline Total & $\mathbf{2 7}$ & $\mathbf{2 7}$ & $\mathbf{2 7}$ & \\
\hline
\end{tabular}

${ }^{a}=$ ANOVA $;{ }^{b}=\overline{\text { Chi Square }}{ }^{c}=$ Kruskal-Wallis

We assessed the samples into several characteristics, such as

Statistically, the distribution of the samples' characteristics among three study groups were normal $(\mathrm{p}>0,05)$. age, ethnicity, religion, education, and body mass index.

Table 2 Incidence of Shivering Among Study Groups

\begin{tabular}{lllll}
\hline Shivering, n (\%) & Pethidine & Dexamethasone & NaCl 0,9\% & p-value \\
\hline Yes & $7(25,9)$ & $10(37,0)$ & $16(59,3)$ & \multirow{2}{*}{$0,040^{*}$} \\
No & $20(74,1)$ & $17(63,0)$ & $11(40,7)$ & \\
\hline Total & $\mathbf{2 7}$ & $\mathbf{2 7}$ & $\mathbf{2 7}$ & \\
\hline
\end{tabular}

Chi Square

Shivering was occurred in all study groups with the incidence in pethidine, dexamethasone, and control group were 7 samples $(25,9 \%), 10$ samples $(37 \%)$, and 16 samples $(59,3 \%)$ respectively $(\mathrm{p}<0,05)$. 
Table 3 Incidence of Shivering Based on Bedside Shivering Assessment Scale (BSAS) Among Study Groups

\begin{tabular}{lllll}
\hline Scale & Pethidine & Dexamethasone & NaCl 0,9\% & p-value \\
\hline $\mathbf{0}$ & $20(74,1)$ & $17(63,0)$ & $11(40,7)$ & \\
$\mathbf{1}$ & $3(11,1)$ & $2(7,4)$ & $1(3,7)$ & \\
$\mathbf{2}$ & $2(7,4)$ & $3(11,1)$ & $5(18,5)$ & $0,011^{*}$ \\
$\mathbf{3}$ & $2(7,4)$ & $4(14,8)$ & $6(22,2)$ & \\
$\mathbf{4}$ & $0(0)$ & $1(3,7)$ & $4(14,9)$ & \\
\hline Total & $\mathbf{2 7}$ & $\mathbf{2 7}$ & $\mathbf{2 7}$ & \\
\hline
\end{tabular}

\section{Kruskal-Wallis}

Grade 0 shivering was the most common type of shivering in all study groups and the percentages were $74,1 \%$, $63 \%$, and $40,7 \%$ in pethidine, dexamethasone, and NS group respectively. Control group showed a higher shivering quality than the experimental groups $(\mathrm{p}<0,05)$. There was no incidence of grade 4 shivering in pethidine group.

\section{CONCLUSION}

The effects of pethidine, dexamethasone, and NS in lowering the incidence of post anaesthesia shivering in caesarean section patients under spinal anaesthesia were statistically significant ( $\mathrm{p}$ value 0,04$)$. There was a significant difference in shivering incidence based on shivering assessment scale among all study groups ( $\mathrm{p}$ value 0,011 ). The quality of shivering was assessed using Bedside Shivering Assessment Scale (BSAS) and the experimental groups showed lower shivering quality than control group.

\section{REFERENCES}

[1] Alfonsi P. Postanaesthetic shivering. Epidemiology, pathophysiology and approaches to prevention and management. Minerva Anestesiol. 2013;69:438-42

[2] Banihashem N, Hasannasab B, Alereza H. Does dexamethasone prevent subarachnoid meperidin-induced nausea, vomiting and pruritus after cesarean delivery? Saudi J Anaesth 2013; 7:138-141

[3] Bhattacharya PK, Bhattacharya L, Jain KR, Agarwal RC. Post Anaesthesia Shivering (PAS): A Review. Indian J. Anaesth [serial online]. 2003; 47 (2) : 88-93.
[4] Crowley L.J. and Buggy D.J.: Shivering and neuraxial anesthesia. Reg Anesth. Pain Med., 33: 241-52, 2018

[5] Entezariasl M., Isazadehfar K.. Dexamethasone for prevention of postoperative shivering: a randomized double-blind comparison with phetidine. International Journal of Preventive Medicine. 2013; 4 : 818-24.

[6] Hadzic, Admir. 2017. Hadzic's textbook of regional anesthesia and acute pain management. 2nd Edition. McGraw-Hill Education: New York

[7] Kelsaka E., Baris S., Karakaya D. And Sarihasan B.: Comparison of ondansetron and meperidine for prevention of shivering in patients undergoing spinal anesthesia. Reg. Anesth. Pain Med., 31: 40-5, 2016.

[8] Khoshrang H, Parvizi A, Haddadi S, Heidarzadeh A. Comparing the Effect of Pethedine, Dexamethasone and Placebo on Preventing Post-operation. Zahedan J Res Med Sci. 2017;9:9-15

\section{AUTHORS}

First Author - Abduh Halim Perdana A, Post graduate of Anaesthesiology and Intensive Therapy, Faculty of Medicine, Universitas Sumatera Utara, Medan, Indonesia, abduhraito@gmail.com

Second Author - Muhammad Ihsan, Anaesthesiology and Intensive Therapy, Faculty of Medicine, Universitas Sumatera Utara, Medan, Indonesia

Third Author - Yutu Solihat, Anaesthesiology and Intensive Therapy, Faculty of Medicine, Universitas Sumatera Utara, Medan, Indonesia

Correspondence Author - Abduh Halim Perdana A, abduhraito@gmail.com, +62 812-6953-2591 